\title{
Prevalence of tuberculous lymphadenitis in Gondar University Hospital, Northwest Ethiopia
}

\author{
Dagnachew Muluye*, Belete Biadgo, Eden W/Gerima and Andebet Ambachew
}

\begin{abstract}
Background: Tuberculous is the leading cause of death worldwide with a large number of deaths occurring in developing countries. Tuberculous lymphadenitis is among the most common presentations of extra pulmonary tuberculous. This study attempts to determine the magnitude of tuberculous lymphadenitis from patients with lymph node aspirate in Gondar University Hospital, Northwest Ethiopia.

Methods: Retrospective study was conducted. Data were collected from registration book of Gondar university Hospital pathology laboratory after checking the completeness of patient's necessary information like age, sex and fine needle aspiration cytology results. Data were entered and analyzed using SPSS version 16 statistical package. Chi-square test was done to determine associations.

Result: A total of 3,440 lymph node aspirates were examined using fine needle aspiration cytology. Of these, 2,392 (69.5\%) cases were found to have tuberculous lymphadenitis. Male $1647(47.9 \%)$ to female $1793(52.1 \%)$ ratio of all study subjects were 0.9:1. Females (54.1\%) were more affected than males (45.9\%). Age, sex and site of aspiration were found to be statistically associated with tuberculous lymphadenitis ( $p$-value $<0.001$ ). The age group of 15-24 years had the highest prevalence of tuberculous lymphadenitis followed by those of 25-34 years old. The most affected sites were cervical lymph nodes (47.5\%) followed by auxiliary (19.4\%) and submandibular (12.9\%) lymph node regions. None of the records documented the HIV status of subjects.

Conclusion: The prevalence of tuberculous from lymph node aspirate was found to be higher involving the frequently affected site of cervical lymph node. The HIV status of patients with all forms of tuberculous should have to be checked and documented. Further prospective and advanced studies are recommended to determine the specific etiologic agents and contributing factors.
\end{abstract}

Keywords: Tuberculous lymphadenitis, Fine needle aspiration cytology, Ethiopia

\section{Background}

Tuberculous (TB) is a chronic bacterial disease caused by a slightly curved non motile, aerobic, non-capsulated and non-spore forming strains of mycobacteria usually Mycobacterium tuberculous [1]. It is a major public health problem in the world and $1 / 3$ of world's population is infected predominantly in developing countries [2]. The magnitude of $\mathrm{TB}$ is higher in the developing world due to various factors including malnutrition, different causes of immune suppression, dual HIV-TB epidemic and increasing causes of drug resistant TB (Multi drug resistant TB (MDRTB), Extreme drug resistant TB

\footnotetext{
*Correspondence: dagne24@gmail.com

School of Biomedical and Laboratory Sciences, College of Medicine and Health Sciences, University of Gondar, P.O. Box. 196, Gondar, Ethiopia
}

(X-DRTB)) [3]. Ethiopia ranks 7th in the list of 22 high burdens countries severely affected by tuberculous [4]. As per WHO global TB report of 2012, the estimated incidence of all forms of TB in Ethiopia was 220/100,000 population [5] and smear positive cases was $63 / 100,000$ population [6].

Extra pulmonary tuberculous (EPTB) affects different organs of human body where tuberculous lymphadenitis (TBLN) is the most common manifestations of all EPTB [7-10]. The most commonly involved lymph nodes were cervical, axilliary, inguinal, abdominal and supra clavicular sites. Cervical lymph nodes are the most commonly affected group of nodes [11]. Tuberculous that affects cervical lymph nodes represents about $50 \%$ of EPTB even though it could vary in different areas [12]. A
C Biomed Central 
number of studies showed higher proportion of tuberculous lymphadenitis among patients in different areas [13-16]. In a study conducted in the rural part of Ethiopia, $72.8 \%$ cases of TBLN were found [17] and the cervical region was the most affected site (74.2\%) followed by the axillaries and inguinal lymph node regions, $20.3 \%$ and $4.3 \%$, respectively [18].

In Ethiopia, there are only few reports concerning TBLN. Particularly in Gondar there is no data that shows the magnitude of TBLN. This study attempts to assess the magnitude of TBLN and provide baseline information for health professionals and other concerned bodies. Therefore, the aim of the study was to assess magnitude of TBLN from patients with lymph node aspirate in Gondar University Hospital.

\section{Methods}

A retrospective study of seven years period from January, 2003 to January, 2007 and January, 2010 to January 2011 was carried out in Gondar University Hospital pathology laboratory registration book. Gondar is found in North West part of Ethiopia, with in the Amhara regional state at about 748 and 175 kilometers away from the capital Addis Ababa and Bahir Dar respectively. The population of the town is about 206,987 as stated in central statistical agency (CSA) of Ethiopia, 2007.

The study populations were all patients with lymph node aspirate in Gondar University Hospital. The study subjects were all patients with lymph node aspirate between January, 2003 and January, 2007 and January, 2010 to January, 2011. All patients with lymph node aspirate between January, 2003 to January, 2007 and January, 2010 to January, 2011 were included in the study by collecting data from the registration book. Records with incomplete data and demographic characteristics were excluded. TBLN diagnosis by cytology was made by examination of the presence of caseous necrosis, epitheloid cell granulomas, multi nucleated giant cells, degenerated epithelioid cell with neutrophil and hetrogeneous lymphoid population plus granulomatous features.

Data were collected by investigators from registration book of Gondar university Hospital pathology laboratory after checking the completeness of patient's necessary information like age, sex and fine needle aspiration cytology results. Data were analyzed using SPSS version 16 statistical package. Data were summarized using descriptive statistics. Association was done using Chi-square test and P-value $<0.05$ were considered statistically significant.

\section{Ethical consideration}

Data were collected after ethical clearance obtained from the School of Biomedical and Laboratory Sciences, College of Medicine and Health Science, University of Gondar. After discussing the purpose and aim of the study, permission was obtained from the Head of Gondar University Hospital pathology laboratory before the data collection.

\section{Result}

A seven year period retrospective study was carried out to determine the prevalence of tuberculous lymphadenitis among patients examined by FNAC at Gondar University Hospital pathology laboratory. A total of 3,440 lymph node aspirates were examined. Out of these, $2,392(69.5 \%)$ were found to have cytological findings suggestive of TBLN and 1,048 (30.5\%) cases were diagnosed as reactive lymphadenitis. Male 1,647 (47.9\%) to female $1,793(52.1 \%)$ ratio of all study subjects were 0.9:1. Tuberculous lymphadenitis was found among 1,098 (45.9\%) males and 1294 (54.1\%) females with an overall prevalence of $69.5 \%$ (Table 1 ). Females are relatively more affected than males. Higher proportion of tuberculous lymphadenitis were found among the age group of $15-24$ years (28.5\%) and 25-34 years $(27.6 \%)$ (Table 1). The most affected sites were cervical lymph nodes 1135 (47.5\%); axilliary 463 (19.4\%) and submandibular 308 (12.9\%). The least affected lymph node sites were the auricular, neck and other sites with 6\%, 4.2\% and $0.5 \%$ respectively (Figure 1 ).

\begin{tabular}{|c|c|c|c|c|}
\hline \multirow[t]{2}{*}{ Variables } & \multicolumn{2}{|c|}{ Tuberculous lymphadenitis } & \multirow[t]{2}{*}{$x^{2}$} & \multirow{2}{*}{$\begin{array}{l}P \\
\text { value }\end{array}$} \\
\hline & Positive (\%) & Negative (\%) & & \\
\hline$\overline{\text { Age }}$ & & & 10.402 & $<0.001$ \\
\hline$<5$ & $108(4.5)$ & $113(10.4)$ & & \\
\hline $5-14$ & $296(12.6)$ & $221(21.1)$ & & \\
\hline $15-24$ & $682(28.5)$ & $255(24.3)$ & & \\
\hline $25-34$ & $660(27.6)$ & $246(23.5)$ & & \\
\hline $35-44$ & $347(14.5)$ & $119(11.4)$ & & \\
\hline$\geq 45$ & $299(12.5)$ & $94(9.0)$ & & \\
\hline Sex & & & 12.271 & $<0.001$ \\
\hline Male & $1098(45.9)$ & $549(52.4)$ & & \\
\hline Female & $1294(54.1)$ & 499 (47.6) & & \\
\hline Site of aspiration & & & 65.749 & $<0.001$ \\
\hline Cervical & $1135(47.4)$ & $423(40.4)$ & & \\
\hline Axillary & $46319.4)$ & $272(28.0)$ & & \\
\hline Inguinal & $150(6.3)$ & $60(5.7)$ & & \\
\hline Supraclavicular & $208(8.7)$ & $43(4.1)$ & & \\
\hline Submandibular & $308(12.9)$ & $182(17.4)$ & & \\
\hline Auricular & $15(0.6)$ & $12(1.1)$ & & \\
\hline Neck & $100(4.2)$ & $40(3.8)$ & & \\
\hline Others & $13(0.5)$ & $16(1.5)$ & & \\
\hline
\end{tabular}




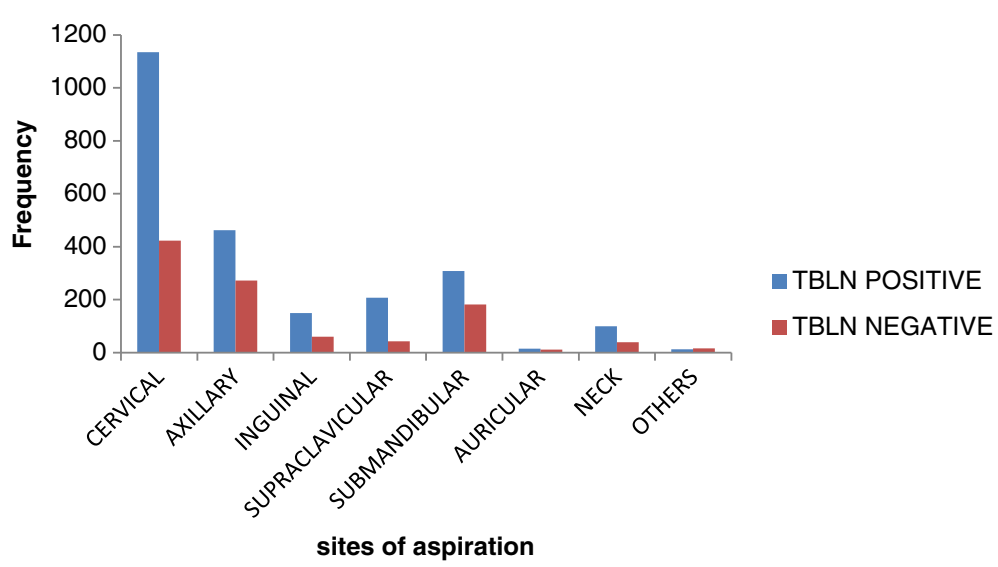

Figure 1 Prevalence of tuberculous lymphadenitis by Site of aspiration among patients with lymph node aspirate in Gondar University Hospital from January, 2003- January, 2007 and January, 2010- January, 2011 G.C.

The trend prevalence of TBLN over the years is fluctuating from 234 to 781 cases. The trend has continued with no great difference in 2003 and 2004 with a total of 623 and 582 TBLN cases but lower in the year 2005 and 2006 that was 453 and 234 cases respectively. In the year 2007, 2010 and 2011, the occurrence rises to 280, 487 and 781 cases respectively (Figure 2).

Age, sex and Site of aspiration were found to be significantly associated with TBLN. The age group of 1524 years had the highest prevalence 682 (28.5\%) followed by those of 25-34 years with $660(27.6 \%)$ and 35-44 years with $347(14.5 \%)$ and $>45$ years with 299 (12.5\%) (P-value $<0.001)$. Tuberculous lymphadenitis was higher in females than males with statistically significant difference ( $\mathrm{p}$-value $<0.001)$. The most affected sites were cervical lymph nodes, axillary and submandibular with statistically significant difference (p-value $<0.001$ ) (Table 1 ). None of the records documented the HIV status of patients.

\section{Discussion}

The prevalence of tuberculous lymphadenitis has been reported to be higher in developing countries like Ethiopia compared to developed countries [2]. In this study, the prevalence of TBLN was $69.5 \%$ which is identical with other study done in Tanzania with prevalence of $69.5 \%$ [14]. Other studies in Israel, Ethiopia and India showed similar figure with prevalence of $70 \%, 72.8 \%$ and $73.75 \%[17,19,20]$ but to some extent higher in another Indian study with prevalence of $83 \%$ [11]. The higher prevalence in this Indian study could be due to the sample size and the time of study where awareness of $\mathrm{TB}$ was poor years ago. In contrast to this study, the prevalence of TBLN was lower in Nigeria (24.45\%), Pakistan (44\%) and India (62\%) $[13,15,21]$. This difference could be due to the different study methods used where small sample size was used in Pakistan and in India. In addition, these studies were onetime studies while our study is retrospective study.

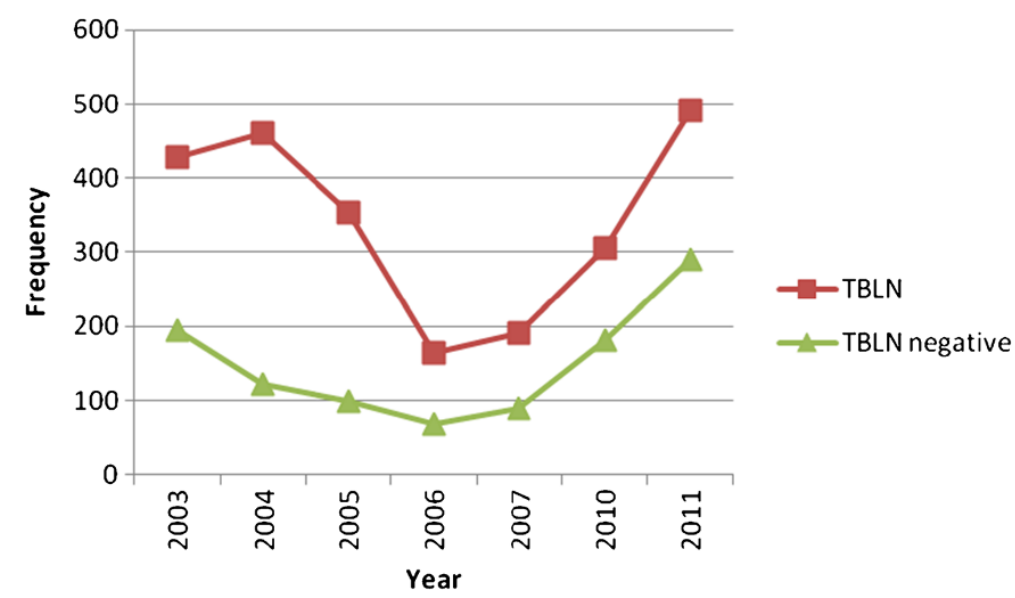

Figure 2 Trend prevalence of tuberculous lymphadenitis among patients with lymph node aspirate in Gondar University Hospital from January, 2003- January, 2007 and January, 2010- January, 2011 G.C. 
The age profile of patients with TBLN showed involvement of younger patients with 15-24 years old being affected accounting $28.5 \%$ followed by 25-34 years old accounting $27.6 \%$ of the cases. This finding is similar to other studies where younger than 30 years old are the commonest age group affected by this disease [18]. Similar study in Nigeria showed the age group of 10-19 years old with highest prevalence (28.1\%) and 20-29 years with $21.8 \%$ which is consistent with our study but the magnitude of the age group 0-9 years has prevalence of $26.3 \%$ which is higher than our study [15]. Male to female ratio of our study is found to be 0.9:1 in which females being highly affected than males with no obvious preponderance in Israel, Pakistan, Nigeria, Ethiopia $[11,15,18,19]$. Cervical lymph node was found to be the most commonly affected site (47.5\%) compared to axillaries and other affected sites. This finding is in agreement with the previous study done in Ethiopia where cervical regions $(74.2 \%)$ being mostly affected site followed by axillary (20.3\%) and inguinal regions (4.3\%) [18] and the study in India and Nigeria were also revealed similar manner $[15,21]$. Historically, tuberculous cervical lymphadenitis has been more common in children and young adults [22].

The trend prevalence of TBLN cases in this study was variable over the years revealing increment in the recent years. The variation in patterns of prevalence of TBLN might be due to TB-HIV co-infection, other immune compromization (chronic diseases) that causes immune suppression and increased risk of developing tuberculous, awareness of people about early diagnosis and treatment of TB patients. Especially in 2003 and 2004 before the era of anti retroviral therapy, the numbers of cases were higher compared to 2005 and 2006. The reason for decreased prevalence in the two consecutive years could be due to lack of service expansion in the hospital hence patients were appointed for more than a month and cannot come back to the hospital. In 2007, 2010 and 2011, there was slight increment in number of cases. This might be due to the increased awareness of community about tuberculous and get diagnosed than the previous years. Increased cases of malnutrition, chronic diseases and MDR-TB could also exaggerate the rate of TBLN in these recent years. The other reason could be increased patient health seeking behavior, service expansion where patients were not appointed not more than a week, well equipped laboratory service and increased number of pathologist by which the quality of the service increased the case detection rate as well as the number of patients compared to the previous years. Previously there was no or one off and on type of pathologist but recently there are at least three actively working pathologists which might contribute for increased case detection rate.
This study tried to assess yet untouched area in the study site. It is very valuable and informative which could give insights for health professionals and policy makers to address the problem. The HIV status of patients with TB (prior emphasis for EPTB) should have to be checked and documented. We couldn't able to include other socio demographic variables which has contribution for tuberculous because of incomplete registration. Lack of the two years data in between due to fire accident on pathology laboratory was also the dare for generalization to the overall trend prevalence.

\section{Conclusion}

The prevalence of TBLN in patients with lymph node aspirate in Gondar University Hospital is high. Among all lymph node sites, cervical region was the predominantly affected site compared to other sites. Female patients were more affected than males. It is important for pathologists to be conscious of tuberculous cases whenever they encounter enlarged lymph node region. The HIV status of patients with TB (prior emphasis for EPTB) should have to be checked and documented. Further prospective and advanced studies are recommended to determine the specific etiologic agents and contributing factors of TBLN in the study area.

\section{Competing interests}

The authors declare that they have no competing interests.

\section{Authors' contributions}

DM: conceived the study, undertook statistical analysis and drafted the manuscript. BB, EW and AA: initiated the study and made major contributions to the data collection and statistical analysis. All authors contributed to the writing of the manuscript and approved the submitted version of the manuscript.

\section{Acknowledgement}

We acknowledge the staff of Gondar University Hospital pathology laboratory for their cooperation during data collection.

Received: 19 September 2012 Accepted: 30 April 2013 Published: 3 May 2013

\section{References}

1. Frieden TR, Sterling TR, Munsiff SS, Watt CJ, Dye C: Tuberculous. Lancet 2003, 362(9387):887-899

2. WHO | Tuberculous: WHO. cited 2012 Jun 8. Available from: [http://www who.int/mediacentre/factsheets/fs104/en/]

3. Ministry of Health, Ethiopia: Available from: [http://www.tbcta.org/ Uploaded_files/Zelf/MinistryofHealthEthiopia1280040820.pdf].

4. WHO: $W H O$ I Global tuberculous control - epidemiology, strategy, financing. cited 2012 Jun 8. Available from: [http://www.who.int/tb/publications/ global_report/2009/en/index.html].

5. WHO: Global tuberculous report. Geneva; 2012.

6. Ethiopian Federal Ministry of Health: First Ethiopian National Population Based Tuberculous Prevalence Survey. Addis Ababa, Ethiopia; 2011.

7. Ishikawa N: How to cope with the global tuberculous burdenexperiences and perspectives for Japan's international cooperation. Kekkaku 2005, 80(2):89-94.

8. Hasan Z, Tanveer M, Kanji A, Hasan Q, Ghebremichael S, Hasan R: Spoligotyping of Mycobacterium tuberculous isolates from Pakistan reveals predominance of Central Asian Strain 1 and Beijing isolates. J Clin Microbiol 2006, 44(5):1763-1768. 
9. Agarwal R, Srinivas R, Aggarwal AN: Parenchymal pseudotumoral tuberculous: Case series and systematic review of literature. Respir Med 2008, 102(3):382-389.

10. ibrt00i4p241.pdf [Internet]: cited 2012 Jun 8. Available from: [http:// medind.nic.in/ibr/t00/i4/ibrt00i4p241.pdf].

11. Dandapat MC, Mishra BM, Dash SP, Kar PK: Peripheral lymph node tuberculous: a review of 80 cases. Br J Surg 1990, 77(8):911-912.

12. Fain $\mathrm{O}$, Lortholary $\mathrm{O}$, Djouab M, Amoura I, Babinet P, Beaudreuil J, et al: Lymph node tuberculous in the suburbs of Paris: 59 cases in adults not infected by the human immunodeficiency virus. Int $J$ Tuberc Lung Dis 1999, 3(2):162-165.

13. Majeed MM, Bukhari MH: Evaluation for granulomatous inflammation on fine needle aspiration cytology using special stains. Patholog Res Int 2011, 2011:851524.

14. Perenboom RM, Richter C, Swai AB, Kitinya J, Mtoni I, Chande H, et al: Diagnosis of tuberculous lymphadenitis in an area of HIV infection and limited diagnostic facilities. Trop Geogr Med 1994, 46(5):288-292.

15. Cadmus SIB, Oluwasola AO, Okolo CA, Bethrand AFN: Pattern of tuberculous lymphadenitis diagnosed by fine needle aspiration cytology at the University College Hospital, Ibadan, Nigeria. Afr J Med Med Sci 2010, 39(3):193-197.

16. Ahmed HGE, Nassar AS, Ginawi l: Screening for tuberculous and its histological pattern in patients with enlarged lymph node. Patholog Res Int 2011, 2011:417635.

17. Yassin MA, Olobo JO, Kidane D, Negesse Y, Shimeles E, Tadesse A, et al: Diagnosis of tuberculous lymphadenitis in Butajira, rural Ethiopia. Scand $J$ Infect Dis 2003, 35(4):240-243.

18. Bezabih M, Mariam D, Selassie S: Fine needle aspiration cytology of suspected tuberculous lymphadenitis. Cytopathology 2002, 13(5):284-290.

19. Weiler Z, Nelly P, Baruchin AM, Oren S: Diagnosis and treatment of cervical tuberculous lymphadenitis. J Oral Maxillofac Surg 2000 58(5):477-481.

20. Kakkar S, Kapila K, Singh MK, Verma K: Tuberculous of the Breast. Acta Cytol 2000, 44(3):292-296.

21. Arora B, Arora DR: Fine needle aspiration cytology in diagnosis of tuberculous lymphadenitis. Indian J Med Res 1990, 91:189-192.

22. Perlman DC, D'Amico R, Salomon N: Mycobacterial infections of the head and neck. Curr Infect Dis Rep 2001, 3(3):233-241.

doi:10.1186/1471-2458-13-435

Cite this article as: Muluye et al.: Prevalence of tuberculous

lymphadenitis in Gondar University Hospital, Northwest Ethiopia. BMC Public Health 2013 13:435.

\section{Submit your next manuscript to BioMed Central and take full advantage of:}

- Convenient online submission

- Thorough peer review

- No space constraints or color figure charges

- Immediate publication on acceptance

- Inclusion in PubMed, CAS, Scopus and Google Scholar

- Research which is freely available for redistribution 